\title{
Numerical Simulation of Tracer Tests in HETEROGENEOUS AQUIFER
}

\author{
By C. Zheng ${ }^{1}$ and J. J. Jiao ${ }^{2}$
}

\begin{abstract}
A large-scale, natural-gradient tracer test in a heterogeneous aquifer at a site near Columbus, Miss. is simulated using three-dimensional (3D) hydraulic conductivity distributions derived from the borehole flowmeter test data. The simulated plume is more sensitive to the way the hydraulic conductivity field is interpolated from the measured data than it is to the dispersivity value. The transport model with longitudinal dispersivities in the range of $1-5 \mathrm{~m}$ can reasonably reproduce the observed plume to a certain concentration limit, but fails to reproduce the significant spreading of the tracer at diluted concentrations as observed in the field. This modeling study illustrates the formidable challenges in modeling and monitoring contaminant transport in very heterogeneous aquifers and points to the needs for new, innovative monitoring techniques that can be applied to characterize the spatial and temporal variabilities in the aquifer properties at scales suitable for detailed transport modeling.
\end{abstract}

\section{INTRODUCTION}

Field studies at well-instrumented sites have played a preeminent role in efforts to better understand and characterize solute transport processes in geologic media. In particular, several recent tracer tests conducted at well-known sites, such as the Borden site in Ontario, Canada [e.g., MacKay et al. (1986); Sudicky (1986)], the Mobile site in Alabama [e.g., Molz et al. (1986)], the Twin Lake site in Ontario, Canada [e.g., Killey and Moltyaner (1988)], the Cape Cod site in Massachusetts [e.g., Garabedian (1987); LeBlanc et al. (1991)], and the Columbus site in Mississippi [e.g., Boggs (1991); Boggs et al. (1992)], have provided new insight and extensive data sets for the development and testing of transport theories and mathematical models.

Two field-scale macrodispersion experiments have been conducted at the Columbus, Miss. site (commonly referred to as the MADE site, an acronym for MAcroDispersion Experiment). The first experiment (MADE-1) was conducted from October 1986 through June 1988, using bromide and three organic tracers. The data from the MADE-1 test were analyzed and reported in a series of papers (Boggs et al. 1992; Adams and Gelhar 1992; Rehfeldt et al. 1992; Boggs and Adams 1992). These papers present an overview of the site condition and monitoring network, geostatistical analysis of the hydraulic conductivity distribution, spatial moment analysis of the bromide plume, and investigation of adsorption and sampling bias. The second experiment (MADE-2) was conducted between June 1990 and September 1991, using both nonreactive and reactive tracers (Boggs et al. 1993).

The primary objective of this paper is to report preliminary results of a modeling study using detailed hydraulic conductivity and concentration data collected for the MADE- 2 test from an extensive three-dimensional (3D) monitoring network. The study is of considerable interest in light of the extreme heterogeneity in the measured hydraulic conductivity distribution at the site. From 2,187 measurements of the hydraulic conductivity using borehole flowmeters in a total of 49 fully penetrating wells, Rehfeldt et al. (1992) indicate that the shal-

\footnotetext{
${ }^{1}$ Assoc. Prof., Dept. of Geol., Univ. of Alabama, P.O. Box 870338 Tuscaloosa, AL 35487-0338. E-mail: czheng@wgs.geo.ua.edu.

${ }^{2}$ Dept. of Earth Sciences, Univ. of Hong Kong, Hong Kong, P.R China.

Note. Associate Editor: Hilary I. Inyang. Discussion open until November 1,1998 . To extend the closing date one month, a written request must be filed with the ASCE Manager of Journals. The manuscript for this paper was submitted for review and possible publication on April/ May, 1996. This paper is part of the Journal of Environmental Engineering, Vol. 124, No. 6, June, 1998. CASCE, ISSN 0733-9372/98/0006$0510-0516 / \$ 8.00+\$ .50$ per page. Paper No. 17671 .
}

low alluvial aquifer at the MADE site is at least 1 order of magnitude more heterogeneous than the aquifers at previous test sites. This makes the tracer tests at the MADE site unique and their numerical simulation challenging.

Another objective of this study is to provide some useful insight on the design of monitoring systems for study of contaminant migration at sites with significant heterogeneities in the aquifer properties. While solute transport models based on the conventional advection-dispersion equation have been commonly employed in field studies (Zheng and Bennett 1995), their application to a heterogeneous site such as the MADE site is severely limited by the lack of sufficiently detailed monitoring data. The tracer tests at the MADE site provide unique opportunities to examine some critical issues, such as the amount of monitoring data needed for adequate modeling of contaminant migration and the uncertainties involved in simulated results due to the lack of detailed monitoring data.

\section{DESCRIPTION OF SITE AND TEST}

\section{Site Characterization}

The study site is located at the Columbus Air Force Base in northeastern Mississippi (Fig. 1). The shallow unconfined aquifer that immediately underlies the site consists of an alluvial terrace deposit with an average thickness of $11 \mathrm{~m}$. The aquifer is composed of poorly sorted to well-sorted sandy gravel and gravely sand with minor amounts of silt and clay. Sediments are generally unconsolidated. Soil facies occur as irregular lenses and layers having horizontal dimensions ranging up to $8 \mathrm{~m}$ and vertical dimensions of $<1 \mathrm{~m}$. Marine sediments, which belong to the Eutaw Formation and consist of clay, silts, and fine-grained sands, form an aquitard beneath the alluvial aquifer. A more detailed description of the site condition is provided in Boggs et al. $(1990,1992)$.

The spatial distribution of hydraulic conductivity at the test site was determined from 2,187 measurements obtained from borehole flowmeter tests conducted in 49 fully penetrating wells. Details of the borehole flowmeter tests are described in Rehfeldt et al. (1992). Fig. 2 shows the depth-averaged distribution of hydraulic conductivity with the apparent presence of a former meander channel. Fig. 3 shows the hydraulic conductivity distribution in the vertical dimension along the approximate tracer plume centerline. The geometric mean of hydraulic conductivity is relatively low, at approximately $5 \times$ $10^{-3} \mathrm{~cm} / \mathrm{s}$, but the variations in the horizontal and vertical directions both range from $2-4$ orders of magnitude. The overall variance of the natural logarithm of hydraulic conductivity is 4.5 (Rehfeldt et al. 1992), which is significantly greater than that of any previously reported tracer test sites (see Table 1). 


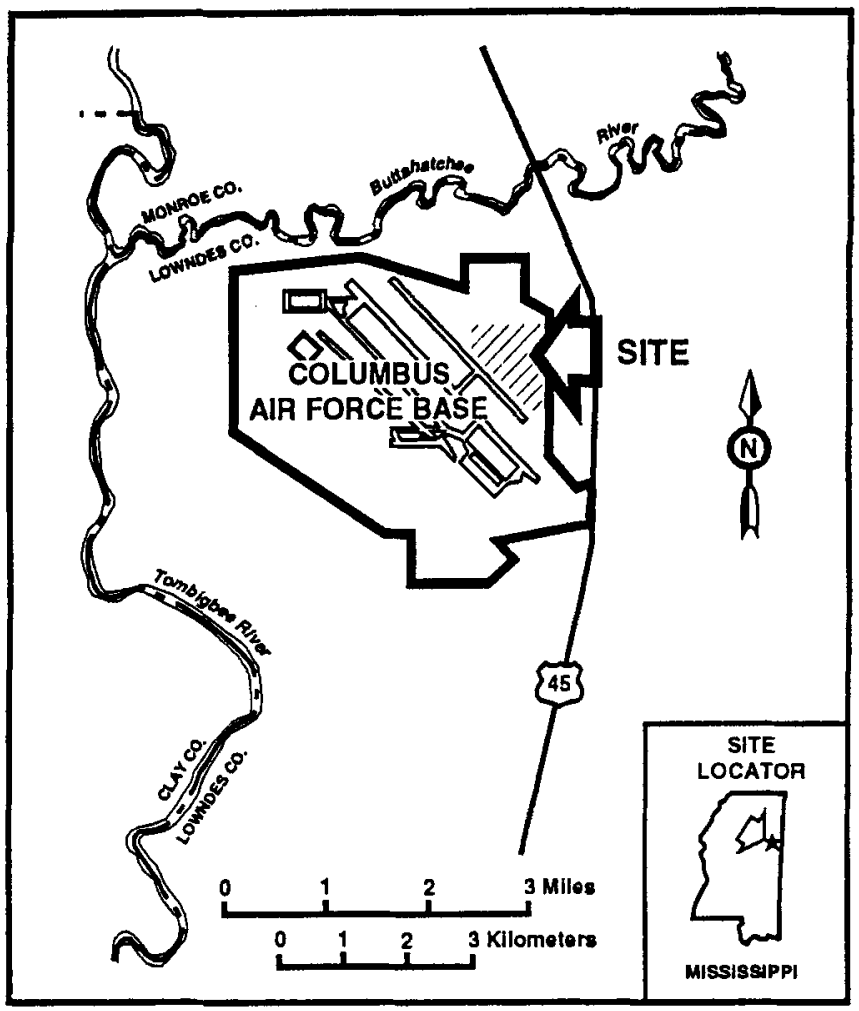

FIG. 1. Location of MADE Site (after Boggs et al. 1990)

The hydraulic head field at the experiment site was monitored with a network of 48 piezometers at different elevations (Boggs et al. 1993) (see Fig. 4). Sixteen of these piezometers were equipped with continuous ground water level recorders. The remainder were monitored at monthly intervals during the study. The hydraulic head field exhibits complex temporal and spatial variability produced by the heterogeneity in the hydraulic conductivity field and the seasonal fluctuations of the water table. Fig. 5 shows a comparison of the potentiometric surfaces constructed from the deep and shallow piezometers using the yearly averaged values of head measurements during the MADE-2 test. The general direction of ground water movement inferred from both potentiometric surfaces is northward, although local differences in the magnitude and direction of the horizontal hydraulic gradient are evident.

\section{Tracer Test}

The MADE-2 natural-gradient tracer experiment was conducted between June 1990 and September 1991. The purpose was to acquire detailed data on the transport of tritiated water and four organic compounds of interest to the utility industry and the military that provided financial support for the study. This paper only discusses the simulation of the tritium tracer.

Details of the MADE-2 test are available in a report prepared by Boggs et al. (1993). The experiment was initiated with a two-day pulse injection of $9.7 \mathrm{~m}^{3}$ of tracer solution into the shallow alluvial aquifer at the test site. Several 3D snapshots of the tracer concentration distributions were performed at one- to three-month intervals during the 15-month experiment using an array of over 300 multilevel samplers. A'total of five spatial samplings or snapshots of the tracer plumes at times of $27,132,224,328$, and 440 days after injection were performed. During the early periods, the observed plumes were influenced by the distribution of the injection wells and the permeability in the vicinity of the injection wells, and so emphasis of this study is given to the plumes observed at later stages that may be controlled more by the general features of the entire site. The plumes at 440 days were, however, not

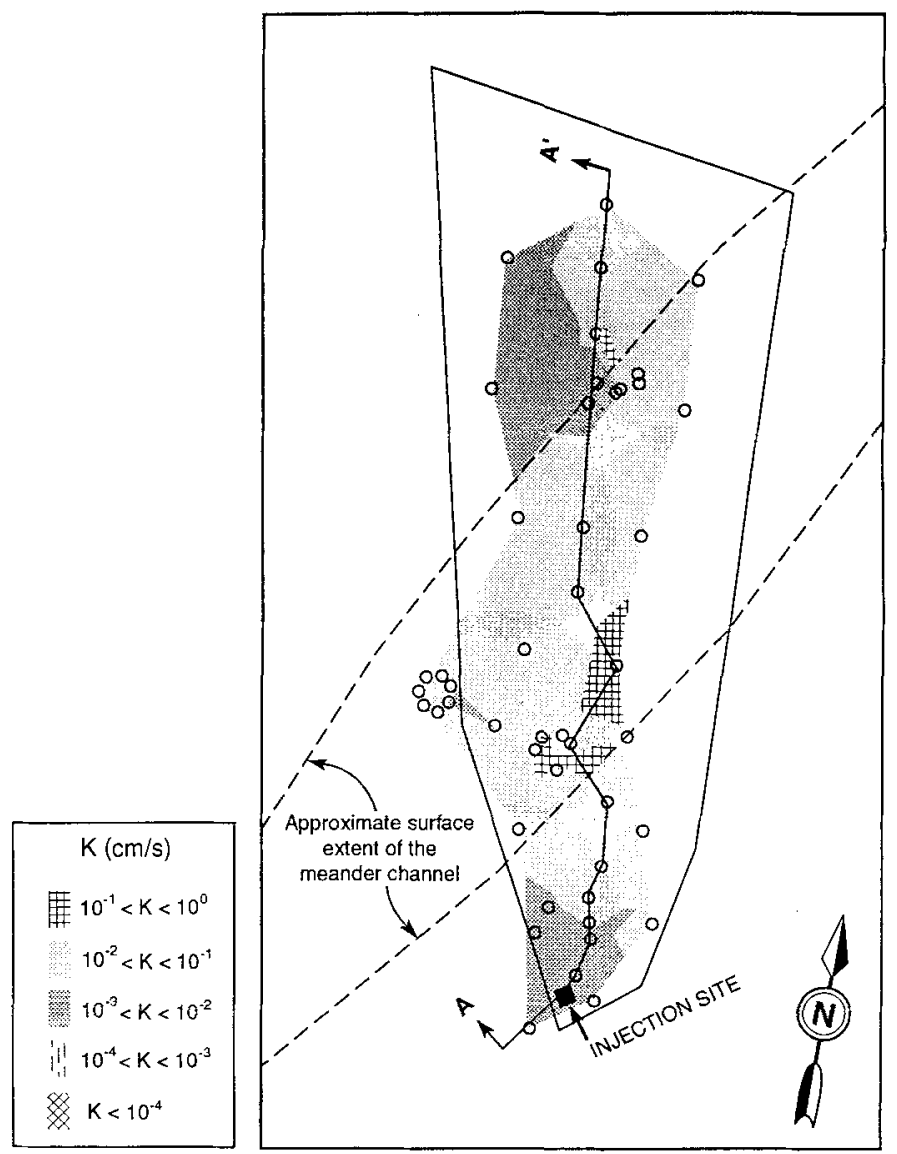

FIG. 2. Depth-Averaged Hydraulic Conductivity Distrlbution Based on Borehole Flowmeter Measurements (Modifled from Boggs et al. 1990). Circles Indicate Locations of Flowmeters

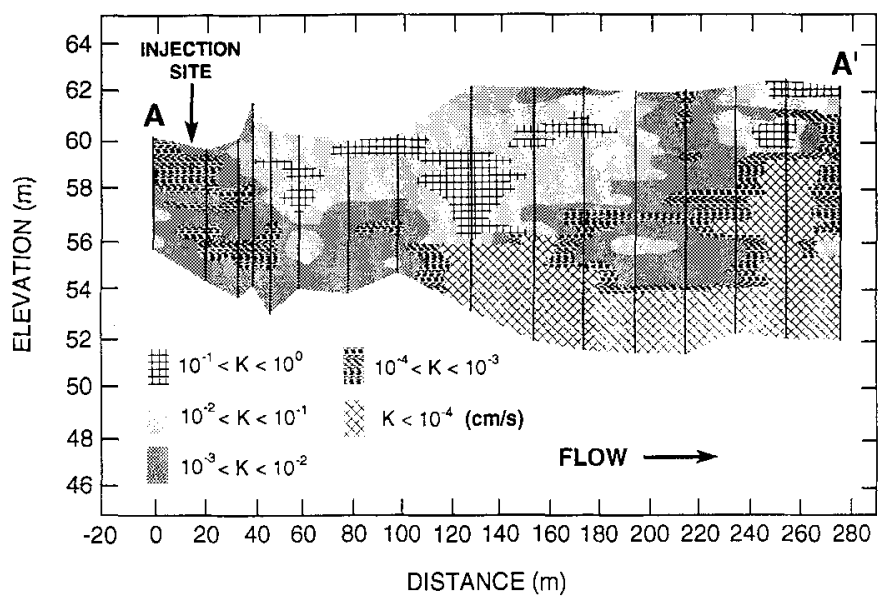

FIG. 3. Hydraulic Conductivity Distribution along Plume Centerline Based on Borehole Flowmeter Measurements (after Boggs et al. 1990). Vertical Lines Indicate Locations of Flowmeters

completely sampled. Thus, this study is only concerned with the first 328 days of the tracer test. The tritium concentration present in field samples was measured with a liquid scintillation analyzer.

The tracer solution was injected through five wells spaced $1 \mathrm{~m}$ apart in a linear array (see the insert in Fig. 4). Each injection well was screened over a $0.6-\mathrm{m}$ interval between $57.5-$ and $58.1-\mathrm{m}$ elevations, approximately halfway between the water table and the aquifer bottom. Injection was conducted over a period of $48.5 \mathrm{~h}$ at a uniform rate of $3.3 \mathrm{~L} / \mathrm{min}$. The maximum increase in hydraulic head in the injection wells was $0.45 \mathrm{~m}$. The injected fluid had a tritium concentration of 
TABLE 1. Variance of Natural Logarithm of Hydraulic Conductivity at Different Tracer Test Sites

\begin{tabular}{c|c}
\hline \hline Test site & Variance \\
$(1)$ & $(2)$ \\
\hline Borden & 0.29 \\
Cape Cod & 0.26 \\
Twin Lake & 0.031 \\
Columbus & 4.5 \\
\hline \hline
\end{tabular}

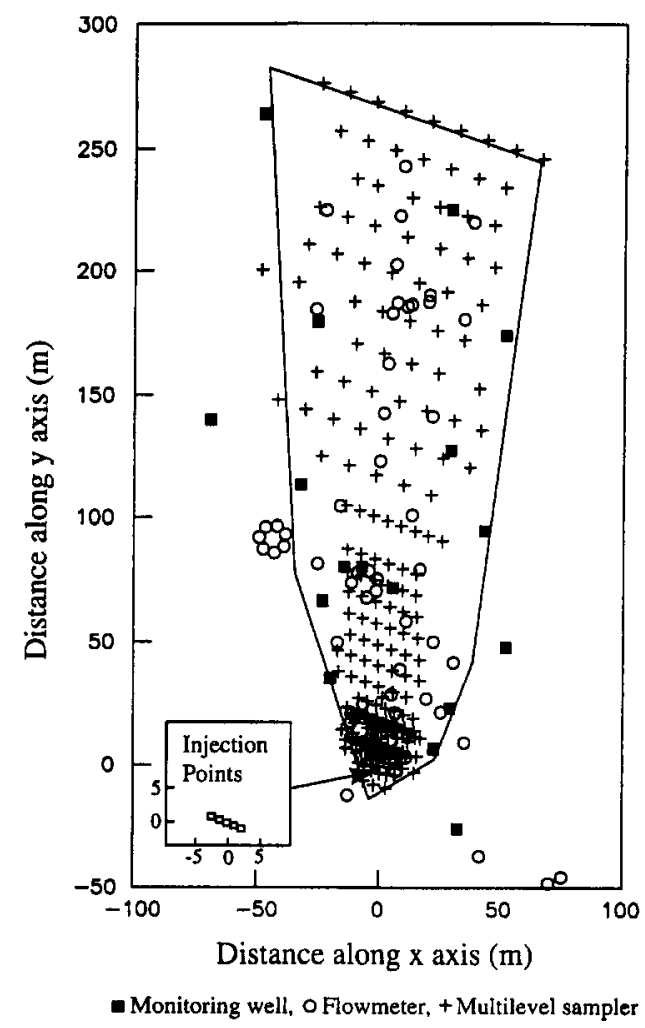

FIG. 4. Plan View of Monitoring Network at MADE Site

$55,610 \mathrm{pCi} / \mathrm{mL}$. The total injected mass (activity) was 0.5387 Ci.

A plan view of the array of the 328 multilevel samplers (MLS) constructed for monitoring the tracer plume in three dimensions is shown in Fig. 4. Each MLS was equipped with 20-30 sampling points spaced $0.38 \mathrm{~m}$ apart in the vertical dimension. The network consisted of over 6,000 sampling points. Ground water samples from each MLS were simultaneously collected.

\section{Observed Plume}

Fig. 6 shows the isosurface of $50 \mathrm{pCi} / \mathrm{mL}$ of the observed tritium plume at 328 days after injection. The plume was generated using the second-order inverse distance interpolation of all measured concentration values. It is highly irregular and significantly fringy. The injection lasted only 2 days, which is short relative to the observation period of 328 days. The plume, therefore, should have traveled a considerable distance from the injection array after such a long observation period. However, the location with the maximum observed concentration of approximately $3,800 \mathrm{pCi} / \mathrm{mL}$ is $<6 \mathrm{~m}$ away from the injection array. This may be explained by the fact that the injection wells are located in the zone with relatively low hydraulic conductivity (see Fig. 2). The tracer was therefore largely "trapped" in this zone. Near the front of the $50-\mathrm{pCi} /$ $\mathrm{mL}$ isosurface there is a small patch that is connected to the main body of the plume by a narrow "neck." This kind of
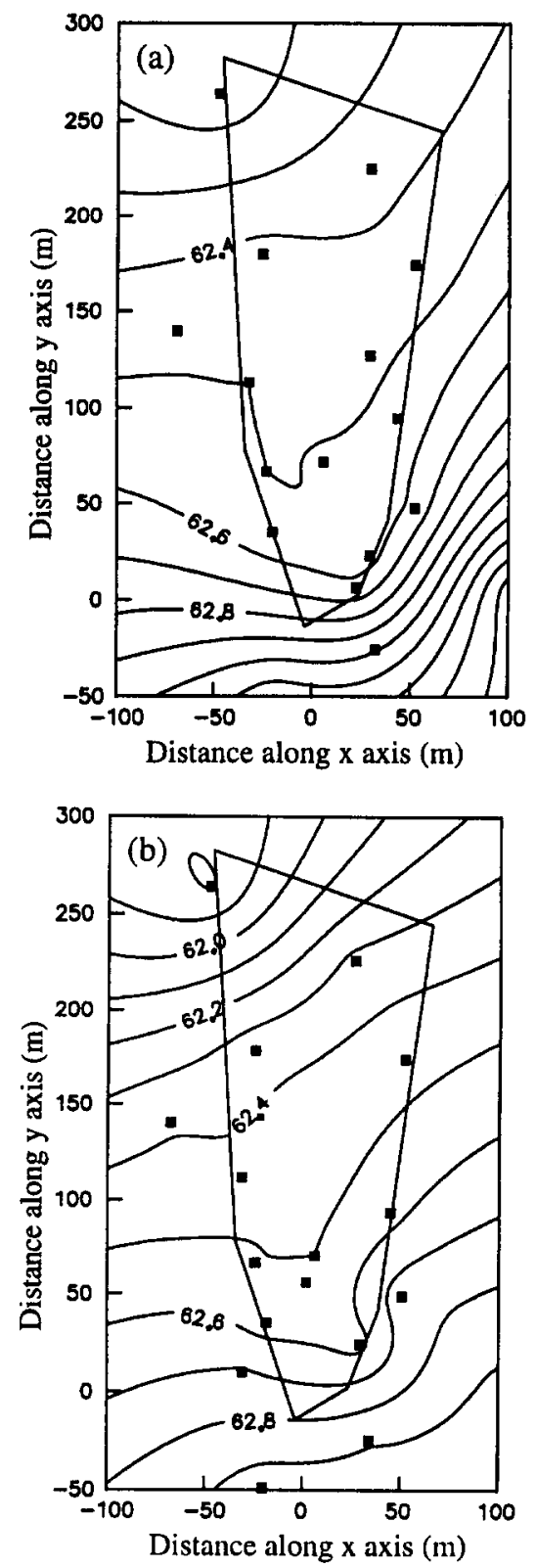

FIG. 5. Contours of Observed Heads: (a) Shallow; and (b) Deep Parts of Aquifer at MADE Site

"head-neck" pattern was also observed for other tracers (not shown here). This indicates the possibility of narrow preferential flow pathways with relatively large hydraulic conductivity. Tracers might have traveled through the preferential flow pathways largely by advection and then spread by dispersion at the fronts of the pathways. This phenomenon is caused by the extreme heterogeneity of the aquifer system and is difficult to reproduce if the hydraulic conductivity field is not represented in great detail.

It should be pointed out that the $50-\mathrm{pCi} / \mathrm{mL}$ isosurface was chosen to represent the observed plume in this study for several reasons. First, it is relatively small compared to the maximum concentration of approximately $3,800 \mathrm{pCi} / \mathrm{mL}$ near the injection point at 328 days after injection $(\sim 1.3 \%)$. Second, the construction of the plume isosurface at lower concentrations necessarily involves more uncertainties caused by data sampling and interpretation. Finally, the spreading of solutes at very diluted concentrations to locations as far as $200 \mathrm{~m}$ away from the injection point is likely caused by the presence of small-scale preferential flow pathways and significant temporal variations in the flow field, neither of which can be rep- 


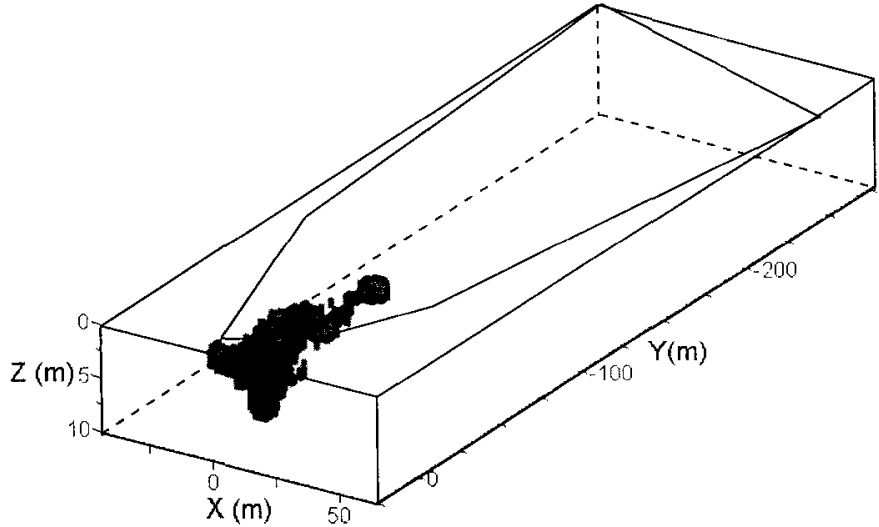

FIG. 6. Observed Tritium Plume Showing lsosurface of $50 \mathrm{pCl}$ $\mathrm{mL} 328$ Days atter Injection

resented in the current model. The intent of this study was to focus on the main body of the observed plume.

\section{MODELING APPROACH}

\section{Spatial Discretization and Boundary Conditions}

A 3D, block-centered, finite-difference grid was designed for modeling of the MADE-2 site. In the horizontal direction, a total of 101 columns and 176 rows with a uniform spacing of $2 \mathrm{~m}$ were used for flow simulation, covering an area 202 by $352 \mathrm{~m}$ (see Fig. 7). Transport simulation was conducted only in the central portion of the model mesh, within which the tritium plume occurred. In the vertical dimension, the alluvial aquifer was discretized into 11 layers with a uniform spacing of $1 \mathrm{~m}$. According to Ababou et al. (1989), the grid spacing should not exceed one-fourth of the spatial correlation length of the hydraulic conductivity field. The horizontal and vertical correlation lengths at the MADE site were estimated to be 12.8 and $1.6 \mathrm{~m}$, respectively (Rehfeldt et al. 1992). In the current model the horizontal spacing meets the correlation length criterion but the vertical spacing does not. However, the vertical spacing of $1 \mathrm{~m}$ is already finer than can be accommodated for in most field applications and is considered adequate for the purpose of this study.

A no-flow boundary was defined at the bottom of the shal-

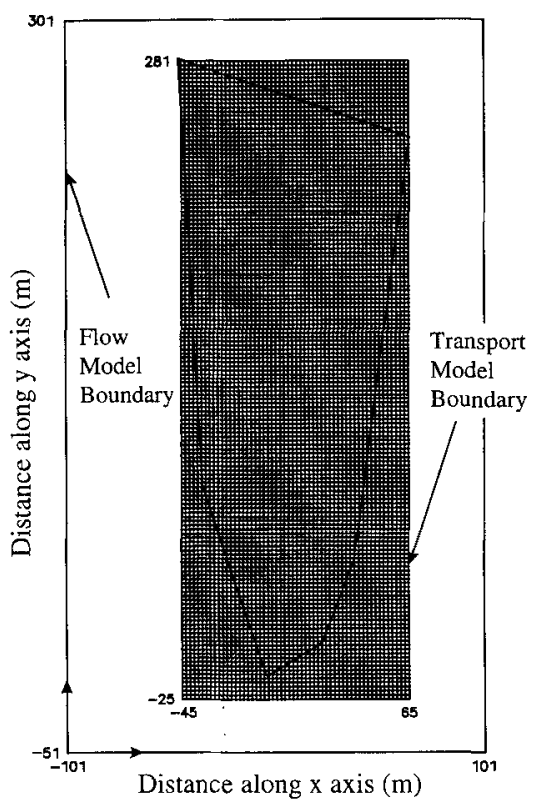

FIG. 7. Boundarles and Finite-Difference Mesh for Flow and Transport Models Used in Study low alluvial aquifer. On top of the model a uniform recharge rate was imposed. Horizontally, specified-head boundaries were defined on the four model borders. The specified heads along the boundaries were calibrated to achieve the best match between the calculated and observed heads at 48 piezometers. The calibration was done manually using the root mean of squared differences between the calculated and observed heads as the calibration criterion.

\section{Simulation and Calibration Procedures}

Only steady-flow simulation was attempted using the MODFLOW code (McDonald and Harbaugh 1988) because detailed data required for transient calibration such as specific yield, storage coefficient, and time-dependent recharge distribution were not available. The steady-state flow equation solved by MODFLOW is as follows:

$$
\frac{\partial}{\partial x_{i}}\left(K_{i i} \frac{\partial h}{\partial x_{i}}\right)+q_{s}=0
$$

where $h=$ hydraulic head; $K_{i i}=$ principal components of hydraulic conductivity aligned with the coordinate axes; and $q_{s}$ $=$ sink/source term.

Because the transport simulation was intended for the tritium plume at 328 days, the hydraulic heads observed within one year of the tracer test were averaged and used as the observed steady-state heads. A first-order trend analysis method was used to generate the initial head distribution for the steady-state flow model from the following equation:

$$
h(x, y, z)=a_{0}+a_{1} x+a_{2} y+a_{3} z
$$

where coefficient $a_{0}=$ a reference background head value; and coefficients $a_{1}, a_{2}$, and $a_{3}=$ hydraulic gradients in the $x-, y$-, and $z$-directions. These coefficients were initially estimated using observed heads at the piezometers. They were then used in (2) to generate a 3D head field. The generated heads at the four specified head boundaries were used as the boundary heads for the flow model. After each trial model run, the calculated heads at the observation points were compared with the observed values. All four coefficients in (2) were adjusted and the boundary heads replaced with newly generated values. This procedure was repeated until a satisfactory match (the root mean of squared differences smaller than $0.1 \mathrm{~m}$ ) was achieved between the calculated and observed heads at the observation points.

Transport modeling was carried out using a version of the MT3D code (Zheng 1990) that was designed to interface with the MODFLOW code for the head solution. The transport equation solved by MT3D is given as follows:

$$
\frac{\partial}{\partial x_{i}}\left(D_{i j} \frac{\partial C}{\partial x_{j}}\right)-\frac{\partial}{\partial x_{i}}\left(v_{i} C\right)+\frac{q_{s}}{\theta} C_{s}-\sum_{k=1}^{N} R_{k}=\frac{\partial C}{\partial t}
$$

where $C=$ solute concentration; $C_{s}=$ concentration of the sink source flux; $\theta=$ porosity; $t=$ time; $D_{i j}=$ dispersion coefficient tensor, a function of dispersivity and seepage velocity, $v_{i}$; and $\sum_{k=1}^{N} R_{k}=$ chemical reaction term. The MT3D code is implemented with several solution options, including the standard finite-difference method and the method of characteristics intended to minimize numerical dispersion for advectiondominated problems. For the range of dispersivity and grid spacing discussed in this paper, the grid Peclet number is so small that the finite-difference method can be used without noticeable numerical dispersion. The grid spacings in both the horizontal and vertical directions for transport modeling are identical to those for flow modeling. The transport only occurred in the central part of the model grid, surrounded by nomass flux boundaries on all sides (Fig. 7).

The tracer was injected into the aquifer over a period of two 
days. To accommodate the injection in the model, the flow field over 328 days was approximated by two instantaneous steady-state stress periods of 2 and 326 days. In the first stress period, the tracer injection through five wells was represented by three cells with the total recharge rate equal to the total injection rate.

\section{Assignment of Hydraulic and Transport Properties}

The measured hydraulic conductivity distribution was directly incorporated into the model by assigning a different hydraulic conductivity value to each model node. Because the number of model nodes used in the simulation is much greater than the number of hydraulic conductivity values collected, an interpolation scheme must be used. Two different approaches, kriging and nearest-grid-point (NGP), were used. In the kriging approach, the hydraulic conductivity measurements were divided into 11 groups based on the elevations of the measurement points. Each group corresponds to one of the model layers. A two-dimensional kriging program (Deutsch and Journel 1992) was then used to generate a hydraulic conductivity distribution for each data group for its corresponding model layer. The exponential variogram structure was used for kriging in each model layer

$$
\gamma(h)=\sigma^{2}\left[1-\exp \left(-\frac{h}{\lambda}\right)\right]
$$

where $\sigma=$ variance of $\ln K$; and $\lambda=$ horizontal spatial correlation length. The variogram structure and related parameters are based on Rehfeldt et al. (1992).

In the NGP approach, the measured hydraulic conductivity value closest to a model nodal point within a maximum search radius was assigned to the nodal point. If there was no data point within the maximum search radius, the mean of all measured hydraulic conductivity values was assigned. Little smoothing was introduced in this procedure.

During the model calibration stage the interpolated hydraulic conductivity distributions based on both kriging and NGP approaches were scaled by a uniform factor to achieve the best match between the calculated and observed heads at all observation points, and also to obtain a general agreement between the observed and calculated displacements of the plume mass center. A scaling factor of 1.2 was used in all simulations.

An average porosity of 0.35 was used for the entire model area, which is close to the value of 0.32 determined from the soil cores collected from the test site (Boggs et al. 1990). The difference in the two values was intended to account for potential consolidation during handling of the core samples (Adams and Gelhar 1992). A uniform recharge rate of $1.4 \times 10^{-4}$ $\mathrm{m} / \mathrm{d}$ was used for the steady-state flow model. To understand the sensitivity of dispersivity on tracer distribution, two cases with constant dispersivities of 1 and $5 \mathrm{~m}$ were simulated. The ratios of the transverse and vertical dispersivities to the longitudinal dispersivity were fixed at 0.01 and 0.001 , respectively, consistent with very limited transverse and vertical dispersion as observed in the field. Tritium is generally considered to be free of sorption and no retardation was included in the simulation.

\section{SIMULATION RESULTS}

Many simulation runs using different combinations of the interpolated hydraulic conductivity fields and transport parameters were tried. Some of the simulated plumes are presented and discussed here.

\section{Simulation with Small Dispersivities}

The simulated tritium plumes using a constant longitudinal dispersivity of $1 \mathrm{~m}$ and the hydraulic conductivity fields gen-

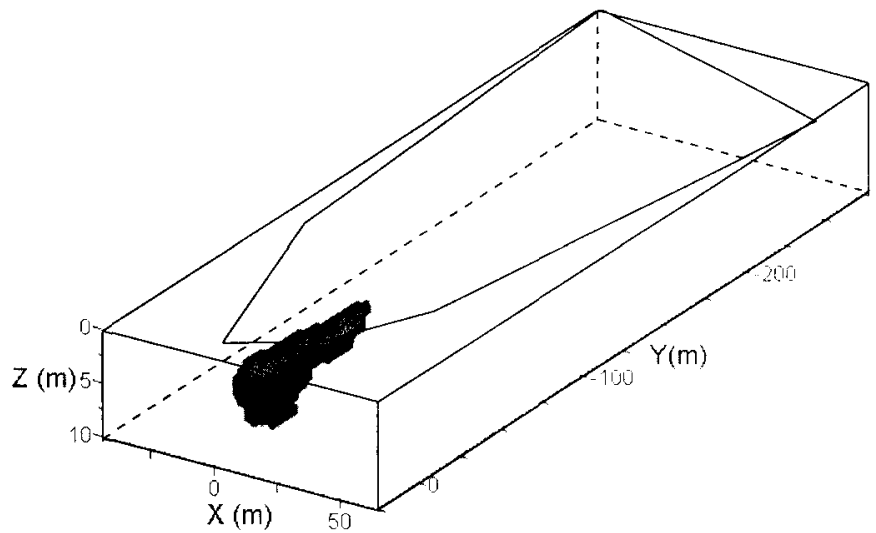

FIG. 8. Simulated Tritium Plume Showing Isosurface of $\mathbf{5 0}$ $\mathrm{pCi} / \mathrm{mL} 328$ Days after Injection. Hydraulic Conductivity Distribution Is Interpolated with Kriging; Longitudinal Dispersivity Used Is 1 m

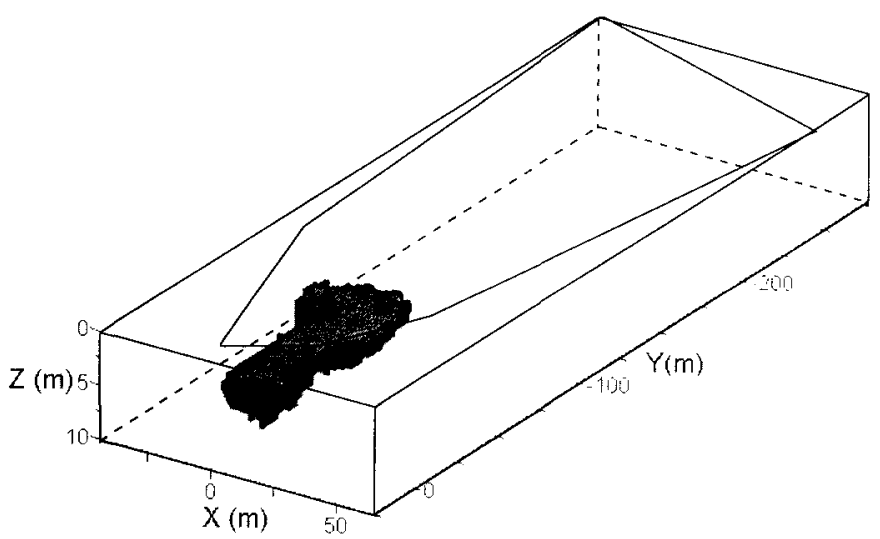

FIG. 9. Simulated Tritium Plume Showing Isosurface of $\mathbf{5 0}$ $\mathrm{pCi} / \mathrm{mL} 328$ Days after Injection. Hydraulic Conductivity Distribution Is Interpolated with NGP Approach; Longitudinal Dispersivity Used is $1 \mathrm{~m}$

erated by both kriging and NGP approaches are shown in Figs. 8 and 9. The simulated plume based on the hydraulic conductivity distribution by the kriging approach shows that a large amount of tracer is trapped near the area of injection (Fig. 8). The plume is progressively smaller toward the front. This is very similar to the observed plume and therefore indicates that the kriging approach generates a hydraulic conductivity field close to the actual distribution. The maximum calculated concentration is approximately $5,300 \mathrm{pCi} / \mathrm{mL}$, as compared with $3,800 \mathrm{pCi} / \mathrm{mL}$ for the maximum observed concentration.

The plume based on the NGP-interpolated hydraulic conductivity distribution shows a much wider front (Fig. 9). This is quite different from the observed plume, but it has some interesting implications. It is clear that the NGP approach introduces more apparent dispersion into the simulated plume. This may be caused by the fact that little smoothing is introduced in obtaining the hydraulic conductivity distribution from the measured data. Furthermore, it is possible that the NGP approach may be able to simulate more closely the significant spreading of tritium at diluted concentrations as observed in the field. Neither the kriging nor the NGP approach can reproduce the fringy feature on the isosurface of the observed plume, and both simulated plumes are much smoother than the observed one.

\section{Simulation with Large Dispersivities}

When the longitudinal dispersivity of $1 \mathrm{~m}$ is used, the general pattern of the simulated plume based on the kriged hydraulic conductivity distribution (Fig. 8) is similar to, but is 


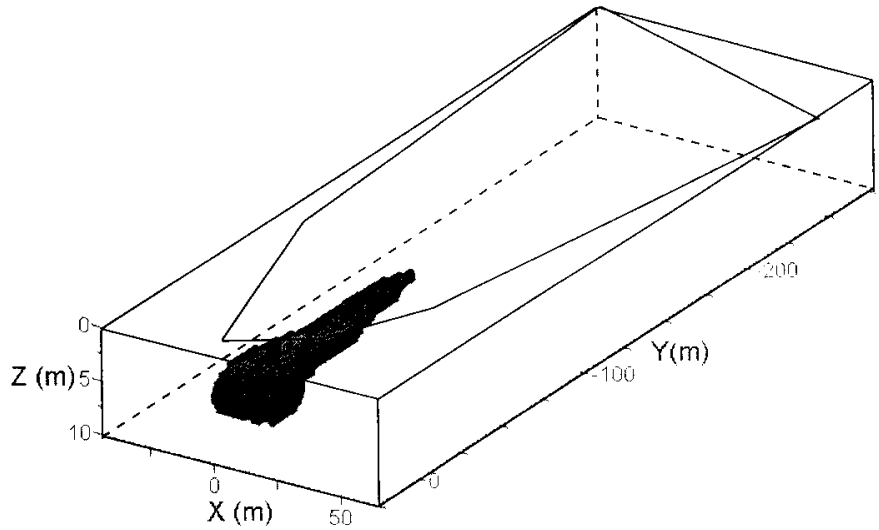

FIG. 10. Simulated Tritium Plume Showing Isosurface of $\mathbf{5 0}$ pCi/mL 328 Days after Injection. Hydraulic Conductivity Distribution Is Interpolated with Kriging; Longitudinal Dispersivity Used ls 5 m

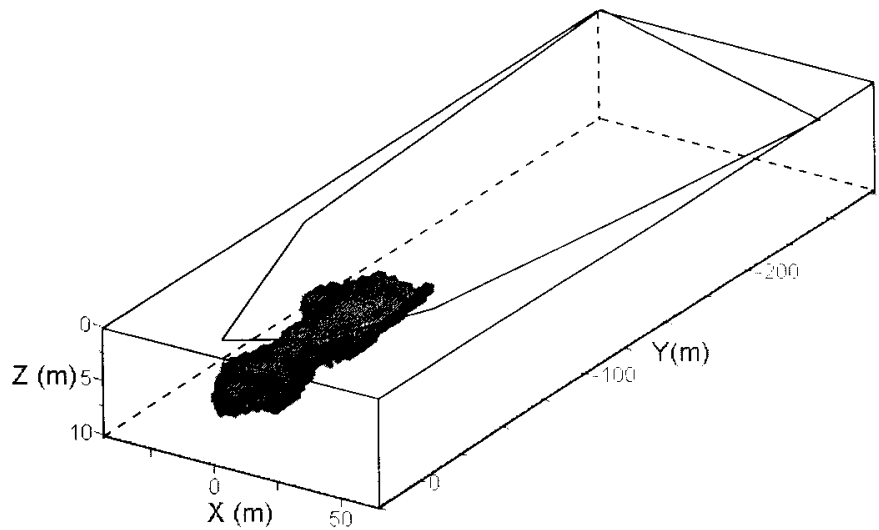

FIG. 11. Simulated Tritium Plume Showing Isosurface of 50 pCi/mL 328 Days after Injection. Hydraulic Conductivity Distribution Is Interpolated with NGP Approach; Longitudinal Dispersivity Used is 5 m

smaller than, the observed one (Fig. 6). The dispersivity is thus increased to $5 \mathrm{~m}$. The simulated plume based on the kriged hydraulic conductivity distribution is shown in Fig. 10. While the overall configuration of the simulated plume using the larger dispersivity seems to match the observed plume (Fig. 6) better than that using the smaller dispersivity (Fig. 8), the maximum simulated concentration decreases from 5,300 to $2,300 \mathrm{pCi} / \mathrm{mL}$, as compared to $3,800 \mathrm{pCi} / \mathrm{mL}$ for the maximum observed concentration.

The simulated plume with a longitudinal dispersivity of 5 $m$ and using the NGP interpolated hydraulic conductivity distribution is shown in Fig. 11. Compared with Fig. 9, based on the same hydraulic conductivity distribution, it can be seen that the impact of increasing the dispersivity value from 1 to $5 \mathrm{~m}$ is not significant. On the other hand, it seems that the interpolation scheme used to generate the hydraulic conductivity distributions for the simulation model from the measured data has a more profound impact as is evident in Figs. 10 and 11 with the same dispersivity value.

\section{SUMMARY AND DISCUSSIONS}

A large-scale natural gradient tracer test in a heterogeneous aquifer at the Columbus site is simulated using $3 \mathrm{D}$ hydraulic conductivity distributions derived from the borehole flowmeter test data through the kriging and NGP interpolation methods. The simulated plume seems to be more sensitive to the way the hydraulic conductivity field is generated from the measured data than to the dispersivity value. The model with the hydraulic conductivity distribution determined by the kriging approach and with a longitudinal dispersivity in the range of 1 to $5 \mathrm{~m}$ most closely captures the main features of the observed plume. However, the highly irregular pattern of the observed plume is difficult to reproduce. In addition, significant spreading of the tracer at very diluted concentrations due to temporal flow field variations and likely preferential flow pathways is not considered in the current model.

The study has general implications on field hydrogeologic investigation and contaminant monitoring design. Compared with the simulated head distribution in the flow model, the simulated concentration distribution in the transport model is much more sensitive to local heterogeneities. Because aquifer heterogeneity is the most important controlling factor for contaminant migration, in a contaminant monitoring system the first priority should be given to understanding the hydraulic conductivity distribution in the aquifer. To monitor the plume distribution, a 3D monitoring network is required. Due to the lack of sufficient monitoring data, very often a $3 \mathrm{D}$ plume is approximated by, or "compressed" to, a 2D one, forcing the model to revert to large dispersivities with greater uncertainty. The density of the observation points should depend on the degree of heterogeneity in the aquifer system. If the aquifer is relatively homogeneous, fewer observation points are required. Because a 3D monitoring system is very costly, the extent of heterogeneities that need to be characterized for a site should be well understood before the monitoring network is installed.

An equally important, but often neglected, aspect of monitoring network design is the temporal variation in the flow field. Due to the lack of sufficiently detailed time-dependent data or for the sake of simplicity, many transport models are approximately based on a steady-state ground water flow model. The distribution of contaminants is very sensitive to the temporal variation in flow direction. If the seasonal change in flow direction is ignored and the fluctuation resulting from the seasonal water level changes is lumped into the dispersion effect, then a large artificial dispersivity is created. This is also a possible limitation for the current modeling study at the Columbus site. The dispersivity value of $5 \mathrm{~m}$ may be overestimated because the seasonal changes in the flow field are ignored.

This modeling study illustrates the formidable challenges in modeling and monitoring contaminant transport in very heterogeneous aquifers. While the deterministic modeling approach as employed in most field-scale studies can be used to approximate the overall plume configuration reasonably well at the MADE site, detailed simulation of the contaminant distribution at diluted concentrations involves significant uncertainties, even with the availability of extensive monitoring data. The study also points to the need for new, innovative monitoring techniques that can be applied to characterize the spatial and temporal variabilities in the aquifer properties at scales suitable for detailed transport modeling.

\section{ACKNOWLEDGMENTS}

The writers thank Tom Stauffer of the U.S. Air Force and other members of the MADE-2 test team for providing the data used in this study. Financial support is provided by a research grant from Cray Research, Inc. The writers are grateful to Daniel Feinstein and Chris Neville for many stimulating discussions and to two anonymous reviewers for their helpful comments.

\section{APPENDIX. REFERENCES}

Ababou, R., McLaughlin, D. B., Gelhar, L. W., and Tompson, A. F. B. (1989). "Numerical simulation of three-dimensional saturated flow in randomly heterogeneous media."' Trans. Porous Media, 4(6), 549-565.

Adams, E. E., and Gelhar, L. W. (1992). "Field study of dispersion in a heterogeneous aquifer. 2: Spatial moments analysis." Water Resour. Res., 28(12), 3293-3307.

Boggs, J. M. (1991). "Database for the First Macrodispersion Experiment 
(MADE-1)." Final Rep. EN-7363, Electric Power Res. Inst., Palo Alto, Calif.

Boggs, J. M., and Adams, E. E. (1992). "Field study of dispersion in a heterogeneous aquifer. 4: Investigation of adsorption and sampling bias." Water Resour. Res., 28(12), 3325-3336.

Boggs, J. M., Beard, L. M., Long, S. E., McGee, M. P., Macintyre, W. G., Antworth, C. P., and Stauffer, T. B. (1993). "Database for the Second Macrodispersion Experiment (MADE-2)." Tech. Rep. TR-102072, Elec. Power Res. Inst., Palo Alto, Calif.

Boggs, J. M., Young, S. C., Beard, L. M., Gelhar, L. W., Rehfeldt, K. R., and Adams, E. E. (1992). "Field study of dispersion in a heterogeneous aquifer. 1: Overview and site description." Water Resour. Res., 28(12), $3281-3291$.

Boggs, J. M., Young, S. C., Benton, D. J., and Chung, Y. C. (1990). "Hydrogeologic characterization of the MADE site." Interim Rep. EN6915, Electric Power Res. Inst., Palo Alto, Calif.

Deutsch, C. V., and Journel, A. G. (1992). GSLIB, geostatistical software library and user's guide. Oxford University Press, New York, N.Y.

Garabedian, S. P. (1987). "Large-scale dispersive transport in aquifers: field experiments and reactive transport theory," PhD thesis, MIT, Cambridge, Mass.

Killey, R. W. D., and Moltyaner, G. L. (1988). "Twin Lake tracer tests: methods and permeabilities." Water Resour. Res., 24(10), 1585-1613.

LeBlanc, D. R., Garabedian, S. P., Hess, K. M., Gelhar, L. W., Quadri, R. D., Stollenwerk, K. G., and Wood, W. W. (1991). "Large-scale natural gradient tracer test in sand and gravel, Cape Cod, Massachusetts.
1: Experimental design and observed tracer movement." Water Resour. Res., 27(5), 895-910.

MacKay, D. M., Freyberg, D. L., Roberts, P. V., and Cherry, J. A. (1986). "A natural gradient experiment on solute transport in a sand aquifer. 1: Approach and overview of plume movement." Water Resour. Res., 22(13), 2017-2029.

McDonald, M. G., and Harbaugh, A. W. (1988). A modular three-dimensional finite-difference ground-water flow model. U.S. Geological Survey Techniques of Water Resour. Investigations, Book 6 .

Molz, F. J., Güven, O., Melville, J. G., Crocker, R. D., and Matteson, K. T. (1986). "Performance, analysis, and simulation of a two-well tracer test at the Mobile site." Water Resour. Res., 22(7), 1031-1037.

Rehfeldt, K. R., Boggs, J. M., and Gelhar, L. W. (1992). "Field study of dispersion in a heterogeneous aquifer. 3: Geostatistical analysis of hydraulic conductivity." Water Resour. Res., 28(12), 3309-3324.

Sudicky, E. A. (1986). A natural gradient experiment of solute transport in a sand aquifer: spatial variability of hydraulic conductivity and its role in the dispersion process." Water Resour. Res., 22(13), 20692082.

Zheng, C. (1990). MT3D: “A modular three-dimensional transport model for simulation of advection, dispersion and chemical reactions of contaminants in groundwater systems." Rep. to U.S. Envir. Protection Agency, Ada, Okla.

Zheng, C., and Bennett, G. D. (1995). Applied contaminant transport modeling: theory and practice. Van Nostrand Reinhold, New York, N.Y. 